\title{
A PROFILE OF PATIENTS REGISTERED AT ART CENTRE AT SURAT MUNICIPAL INSTITUTE OF MEDICAL EDUCATION \& RESEARCH IN SURAT CITY, GUJARAT, INDIA
}

\author{
Modi B, Patel P, Patel S \\ Department of Community Medicine, Surat Municipal Institute of Medical Education \& Research (SMIMER), \\ Surat, India
}

\begin{abstract}
Introduction: An estimated 2.4 million Indians are currently living with HIV. In India, the antiretroviral treatment program started with a free ART treatment in 2003. This study was conducted in order to understand the clinico-epidemiological profile of patients attending ART centre and the effectiveness of the therapy.
\end{abstract}

Methodology: A cross sectional study was conducted at an ART center of Surat Municipal Institute of Medical Education and Research (SMIMER), in Surat city of Gujarat State. The data of 2357 PLHAs (People Living with HIVI AIDS) registered at ART centre in one year time duration starting from 21st January 2010 was included in the study.

Results: Among the total 2357 subjects, $1483(63 \%)$ were males. In our study $42.3 \%$ of patients were between 31 to 40 years of age. Among the employed subjects, $32.9 \%$ of patients were laborer. Voluntary Counseling and Testing Centre (VCTC) was most common entry point of patient with $50 \%$ followed by private practitioner with $23 \%$ and NGOs with $6.2 \%$. Other entry points are self referred, RNTCP etc. Tuberculosis and diarrhoea were the most common opportunistic infections. There was significant improvement in CD4 count, bodyweight and functional status of the subjects after receiving the ART for an average duration of 6 months.

Conclusion: The economically productive \& sexually active people and those with lesser education are at higher risk of becoming sero-positive. The subjects showed significant improvement after receiving ART with respect to the CD4 count and average body weight.

Key words: ART, Sero-positives, Opportunistic infections, VCTC

\section{INTRODUCTION}

The first case of HIVIAIDS in India was identified in Chennai in 1986. ${ }^{1}$ And 24 years later, around 2.4 million Indians are HIV positive. ${ }^{2}$ According

\begin{tabular}{l}
\hline Correspondence: \\
Dr. Bhautik Modi \\
MBBS \\
Resident, Department of Community Medicine \\
Surat Municipal Institute of Medical Education \& \\
Research (SMIMER), Surat, India \\
E-mail: dr_bhautikmodi@yahoo.co.in \\
\hline
\end{tabular}

to the National AIDS Control Organization HIV prevalence rate in India is $0.34 \%(0.25 \%-0.43 \%)$. $^{3}$ The prevalence rate of HIV in Gujarat is $0.25 \% .{ }^{4}$ As HIV treatment programs are implemented across the world, increasing numbers of HIV-infected persons are being treated with antiretroviral therapy (ART). In India, the antiretroviral treatment program started with a free ART treatment in 2003. Although data gathered by National AIDS Control Organization (NACO) in 2007 has revealed that HIV prevalence has stabilized, at least in Tamil Nadu, 
Andhra Pradesh, Karnataka and Maharashtra, it is increasing in at-risk populations in other states. As a result, overall HIV prevalence has continued to rise. ${ }^{5}$ Despite the fact that ART is provided free by the government, there are a large number of seropositive people who do not come forward to receive treatment. Non-adherence is another aspect even when they come for ART. These problems affect the overall success of the programme. ${ }^{6}$ There is a need to study the profile of patients who come to ART centres and their clinical and socio demographic profile. Therefore, the study was conducted in order to understand the clinico-epidemiological profile of patients attending ART centres and the effectiveness of the therapy. This information can be utilized to enhance the utility and adherence to therapy among attendees.

\section{METHODOLOGY}

A cross sectional study was conducted at an ART center of Surat Municipal Institute of Medical Education and Research (SMIMER), a tertiary care hospital and one of the teaching hospitals in Surat city of Gujarat State. Surat is a rapidly developing area, resulted in a high number of migrating and transit populations contributing to the HIVIAIDS disease burden in the area. The SMIMER hospital caters to patients from neighboring districts also. The data of 2357 PLHAs (People Living with HIVI AIDS) registered at ART centre in one year time duration starting from $21^{\text {st }}$ January 2010 was included in the study. Permission was obtained from the Gujarat State AIDS Control Society (GSACS) and the in charge Medical Officer of the ART centre; following which the data was collected using the records of the PLHAs. The demographic information of the subjects was collected along with the clinical profile, place of referral for ART and the treatment details. The clinical staging was done according to the WHO clinical staging of HIVIAIDS (2005) Stage I: HIV infection is asymptomatic and not categorized as AIDS Stage II: includes minor mucocutaneous manifestations and recurrent upper respiratory tract infections and unexplained weight loss ( $<10 \%$ of presumed or measured body weight) Stage III: includes unexplained chronic diarrhea for longer than a month, severe bacterial infections and pulmonary tuberculosis and unexplained weight loss (>10\% of presumed or measured body weight) Stage IV: includes toxoplasmosis of the brain, candidiasis of the esophagus, trachea, bronchi or lungs and Kaposi's sarcoma; these diseases are indicators of AIDS.

The functional status of the subjects was done as working, ambulatory and bed ridden.7 The records with incomplete information were excluded from the study. Data was entered and analyzed using Epiinfo statistical software and the results presented as proportions in the form of tables. For statistical analysis, paired t-test test was used and $p<0.05$ was considered significant.

\section{RESULTS}

\section{Socio-demographic profile of sero-positives}

Our study included 2357 sero-positive patients who had received ART. Table 1 shows the demographic profile of the study population. Among the subjects, 1483 (63\%) were males. In our study $42.3 \%$ of patients were between 31 to 40 years of age. Interesting to note that, out of total 862 female patients, maximum 344 (40\%) were from age group of 20 to 30 years. Where as, maximum number of male patients that is $688(46.4 \%)$ were from age group of 30 to 40 years.

Table 1. Socio-demographic characteristics of the study population $(n=2357)$

\begin{tabular}{|c|c|c|c|c|c|}
\hline \multicolumn{2}{|c|}{ Characteristic } & Males (\%) & Females (\%) & Transgender (\%) & Total (\%) \\
\hline \multirow{6}{*}{$\begin{array}{l}\text { Age group } \\
\text { (years) } \\
n=2354 \\
\text { [Data of } 3 \\
\text { patients not } \\
\text { available] }\end{array}$} & $\leq 10$ & $36(2.4)$ & $25(2.9)$ & 0 & $61(2.6)$ \\
\hline & $11-20$ & $25(1.7)$ & $36(4.2)$ & 0 & $61(2.6)$ \\
\hline & $21-30$ & $342(23.1)$ & $344(40.0)$ & $5(55.6)$ & $691(29.4)$ \\
\hline & $31-40$ & $688(46.4)$ & $304(35.3)$ & $4(44.4)$ & $996(42.3)$ \\
\hline & $40-50$ & $296(19.9)$ & $118(13.7)$ & 0 & 414(17.6) \\
\hline & $>50$ & $96(6.5)$ & $35(4.1)$ & 0 & $131(5.5)$ \\
\hline
\end{tabular}


Table 1. Continuous

\begin{tabular}{|c|c|c|c|c|c|}
\hline \multirow{6}{*}{$\begin{array}{c}\text { Marital status } \\
\mathrm{n}=2354 \\
\text { [Data of } 3 \\
\text { patients not } \\
\text { available] }\end{array}$} & Unmarried & 171(11.5) & $36(4.2)$ & $5(55.6)$ & 212(9.0) \\
\hline & Married & $1150(77.6)$ & $575(66.7)$ & $2(22.2)$ & $1727(73.4)$ \\
\hline & Divorced & $38(2.6)$ & $21(2.4)$ & 0 & $59(2.5)$ \\
\hline & Widow/ Widower & $86(5.8)$ & $210(24.4)$ & 0 & $296(12.6)$ \\
\hline & Separated & $36(2.4)$ & $20(2.3)$ & 2(22.2) & $58(2.5)$ \\
\hline & $\begin{array}{l}\text { Live-in } \\
\text { Relationship }\end{array}$ & $1(0.1)$ & $1(0.1)$ & 0 & $2(0.1)$ \\
\hline \multirow{4}{*}{$\begin{array}{c}\text { Educational } \\
\text { Status(n=2350) } \\
\text { [Data of } 7 \\
\text { patients not } \\
\text { available] }\end{array}$} & Illiterate & $273(18.4)$ & $307(35.7)$ & $2(22.2)$ & $582(24.8)$ \\
\hline & Primary School & $666(45.0)$ & $301(35.0)$ & $4(44.4)$ & $971(41.3)$ \\
\hline & $\begin{array}{l}\text { Secondary } \\
\text { School }\end{array}$ & 497(33.6) & $226(26.2)$ & $3(33.3)$ & $726(30.9)$ \\
\hline & Collage \& above & $44(3.0)$ & $21(3.1)$ & 0 & $71(3.0)$ \\
\hline \multirow{6}{*}{$\begin{array}{c}\text { Employment } \\
\text { Status } \\
n=2357\end{array}$} & Unemployed & 130(8.8) & $75(8.7)$ & 0 & 205(8.7) \\
\hline & Student & $31(2.1)$ & $17(2.0)$ & 0 & $48(2.0)$ \\
\hline & Service & $539(36.3)$ & $21(3.3)$ & 1(11.1) & $569(24.2)$ \\
\hline & Self-employed & $155(10.5)$ & $12(1.4)$ & $3(33.3)$ & $170(7.2)$ \\
\hline & Labourer & $626(42.2)$ & 144(16.7) & $5(55.6)$ & $775(32.9)$ \\
\hline & Housewife & $2(0.1)$ & $588(68.1)$ & 0 & $590(25.0)$ \\
\hline
\end{tabular}

Around $9 \%$ of patients were unmarried. Overall, $86.3 \%$ of the subjects were from Choriyasi taluka of Surat District. Among the total 862 female attendees 588 (68.1\%) were housewife. Among the employed subjects, $32.9 \%$ of patients were labourer. Voluntary Counseling and Testing Centre (VCTC) was most common entry point of patient with $50 \%$ followed by private practitioner with $23 \%$ and NGOs with $6.2 \%$. (Table 2).

Table 2. Entry point of PLHAs $(n=2347)^{*}$

\begin{tabular}{|c|c|c|c|c|}
\hline Entry Point & Males (\%) & Females (\%) & Transgender (\%) & Total (\%) \\
\hline VCTC & $712(48.4)$ & $452(52.8)$ & $5(55.6)$ & $1169(50.0)$ \\
\hline TB/RNTCP & $44(3.0)$ & $10(1.2)$ & 0 & $54(2.3)$ \\
\hline PPTCT & $13(0.9)$ & $47(5.5)$ & 0 & $60(2.6)$ \\
\hline Private & $363(24.7)$ & $174(20.3)$ & $1(11.1)$ & $538(23.0)$ \\
\hline NGO & $110(7.5)$ & $35(4.1)$ & $1(11.1)$ & $146(6.2)$ \\
\hline Self referred & $66(7.7)$ & $50(3.4)$ & $2(22.2)$ & $118(5.0)$ \\
\hline Other & $164(11.1)$ & $88(10.3)$ & 0 & $262(11.2)$ \\
\hline
\end{tabular}

* Data of 10 patients are not available

\section{Clinical profile of study subjects}

The functional status of sero-positive attendees revealed (Table 3 ) that $89.9 \%$ of the study subjects were in "working", $8.3 \%$ were in "ambulatory" stage and $1.8 \%$ were bed-ridden. As per the WHO staging, at the time of registration, $60.6 \%$ of subjects were in stage 1 and $18.9 \%$ were in Stage 2 and $14.70 \%$ were from stage 3 (Table 4). Among total attendees $8.10 \%$ had Tuberculosis. 
Table 3. Functionality status of subjects $(n=2336)^{*}$

\begin{tabular}{|l|c|c|c|c|}
\hline \multicolumn{1}{|c|}{ Characteristic } & Male (\%) & Female (\%) & Transgender (\%) & Total (\%) \\
\hline Working & $1301(88.4)$ & $792(92.6)$ & $8(88.9)$ & $2101(89.9)$ \\
\hline Ambulatory & $139(9.4)$ & $55(6.4)$ & 0 & $194(8.3)$ \\
\hline Bedridden & $32(2.2)$ & $8(0.9)$ & $1(11.1)$ & $41(1.8)$ \\
\hline
\end{tabular}

${ }^{*}$ Data of 21 patients are not available

Table 4. WHO clinical staging of HIVIAIDS (During first visit) $(n=2327)^{*}$

\begin{tabular}{|l|c|c|c|c|}
\hline \multicolumn{1}{|c|}{ WHO Stage } & Male (\%) & Female (\%) & Transgender (\%) & Total (\%) \\
\hline Stage 1 & $547(64.4)$ & $858(58.4)$ & $6(66.7)$ & $1411(60.6)$ \\
\hline Stage 2 & $176(20.7)$ & $263(17.9)$ & $1(11.1)$ & $440(18.9)$ \\
\hline Stage 3 & $98(11.5)$ & $244(16.6)$ & $1(11.1)$ & $343(14.7)$ \\
\hline Stage 4 & $29(3.4)$ & $103(7.0)$ & $1(11.1)$ & $133(5.7)$ \\
\hline
\end{tabular}

${ }^{*}$ Data of 20 patients are not available

Health status of the sero-positives before and after ART

Table 5 shows the comparison of the CD4 count and weight before and after receiving the ART of 1346 PLHAs. The mean CD4 count and the body weight of the subjects increased after receiving ART. There was a statistically significant difference in both CD4 count and weight; before and after receiving the ART on an average for 6 months. (Paired t- test and $<0.05-$ level of statistical significance).

Table 5. Comparison of Health status of the subjects before and after receiving ART ( $n=1346)^{*}$

\begin{tabular}{|l|l|l|l|l|}
\hline \multicolumn{1}{|c|}{ Characteristic } & \multicolumn{1}{|c|}{ Before ART $(\mathbf{n}=1346)$} & After ART $(\mathbf{n}=1346)$ & Difference of Mean & p value \\
\hline CD4 count & 156.24 & 328.91 & 172.67 & $<0.0001 \#$ \\
Mean $(95 \% \mathrm{Cl})$ & $(151.41-161.07)$ & $(322.54-335.28)$ & & \\
\hline Weight $(\mathrm{kg})$. & 43.81 & 51.42 & 7.61 & $<0.0001 \#$ \\
Mean $(95 \% \mathrm{Cl})$ & $(43.19-44.43)$ & $(50.80-52.04)$ & & \\
\hline
\end{tabular}

* Out of total 2357 PLWHA registered, 1346 were put on ART

\# Paired $t$-test and $<0.05$ - level of statistical significance

\section{DISCUSSION}

The present study revealed that males constituted $63 \%$ of the total subjects which was almost equal to National figures, i.e. $61 \% .{ }^{5}$ Result of other study done at Manglore shows $64.4 \%$ of patients were male, which is consistent with results of our study. ${ }^{8}$ This is similar to the findings in a study conducted in the Udupi District by Kumar A et al. ${ }^{9}$ Similar observation was made by Sarna $A$ et al6 and Cauldbeck et al in Banglore ${ }^{10}$, where majority of the attendees were male(84\%).

Majority of the subjects belonged to the age group 31-40years (42.3\%). Our study results were consistent with that of study by Cauldbeck et al which had $50 \%$ of the subjects in 30 to 40 years age group and the overall mean age of the subjects 39.9 years. 10 The distribution according to marital status showed that unmarried subjects constituted only $9 \%$. In comparison with study done at Manglore which had $58.45 \%$ married patient registered, our study shows higher number of them registered at the ART centre. 8 This indicates more number of married patients taking ART at the centre and important role of PPTCT in the institution.

The distribution according to educational status showed that the sero-positivity was higher among the subjects with lesser education. These findings 
are similar to the study conducted by Jayaram $S$ et $\mathrm{al}^{11}$ and to that of the study conducted by Safren SA et al $(17 \%)^{12}$ though the number of subjects with primary education was lesser than those with secondary education and above. But Cauldbeck et al observed no trends for education level with respect to the seropositivity. ${ }^{10}$

In our study, maximum (32.9\%) patients were labourer, reveals more prevalence of HIV in this group of people. Low education status, migration and less awareness regarding safe sex can be the reason for high prevalence among this group of people.

Among the total 862 female attendees 588 (68.1\%) were housewife. This result is higher than the study conducted by Kumar A et al (44.5\%). ${ }^{9}$

The reason for more number of attendees those were housewife can be gaining of infection by unsafe sex from their HIV positive husband or any other sexual partner. This point-out the unsafe sexual practices among married couple.

In our study, $86.3 \%$ of the subjects were from Choriyasi taluka of Surat District. In the present study VCTC centre was most common entry point of patient with $50 \%$ followed by private practitioner with $23 \%$ and NGOs with $6 \%$. Other entry points like PPTCT, TB, In and Out patients, PLHA network, MSM network and STI clinic were contributing less than $5 \%$. Patients self-referral rate was around $5 \%$.

Study at Manglore shows that $84.1 \%$ have availed the services through VCTC and $9.4 \%$ referred from NGO ${ }^{8}$ This point out lower rate of referring from VCTC at Surat. And there is a need to focus to lower the loss of patient from VCTC.

Tuberculosis and diarrhoea were the most common opportunistic infections. These findings were similar to the study conducted by Sharma SK et al $(71 \%)$ in North India ${ }^{13}$ and Kumarasamy $\mathrm{N}$ et al in South India. ${ }^{14}$ In our study, the health status of seropositives revealed improvement in the CD4 count, average body weight and functional status of the subjects after receiving ART indicating efficacy of ART (Table 5). Pant Pai $\mathrm{N}$ et al in San Francisco also observed an improvement in CD4 cell counts after continuous ART therapy for HIVIAIDS. ${ }^{15}$

\section{CONCLUSION}

More than half of the subjects were in economically productive age group and majority of patients who sought ART were males. People from outside the district under study also sought ART from the study area. TB and diarrhoea were the most common opportunistic infections. The subjects showed significant improvement in CD4 count and average body weight after receiving ART.

\section{ACKNOWLEDGEMENTS}

Authors would like to thank GSACS for allowing to use ART data for the study. Authors are also grateful to staff members of ART center, SMIMER, Surat for their kind co-operation.

\section{REFERENCES}

1. www.unicef.org/india/children_2358.htm(accessed on $27 / 10 / 2010$ )

2. Department of AIDS Control, Ministry of Health and Family Welfare, Government of India, Annual Report 2008-2009, National AIDS Control Organization, 2009

3. www.mohfw.nic.in/NFHS-3 HIV Prevalence.ppt (accessed on 27/10/2010)

4. www.avert.org/india-hiv-aids-statistics.htm accessed on 27/10/2010

5. NACO: National AIDS Control Programme PhaseIII (2007-2012): strategy and implementation plan; Ministry of Health and Family Welfare; Govt. of India: 2006.

6. Sarna A, Pujari S, Sengar AK, Garg R, Gupta I, Van Dam J. Adherence to antiretroviral therapy \& its determinants amongst HIV patients in India. Indian J Med Res 2008;127:28-36. 
7. World Health Organization. Clinical staging of HIV/ AIDS. Available from URL http://www.who.int/hiv/ pub/guidelines/en/ (accessed on 10-12-2009).

8. Badiger S, Thapar R, Mithra PP, et al. A profile of patients attending an Anti Retroviral Therapy (ART) Centre at a tertiary care hospital in South India. AMJ 2010;3(6):344-348.

9. KumarA, Kumar P, Gupta M, KamathA, Maheshwari A, Singh S. Profile of Clients Tested HIV positive in a Voluntary Counseling and Testing Center of a District Hospital, Udupi, South Kannada. Ind J Commu Med 2008;33(3):156-9.

10. Cauldbeck MB, O'Connor C, O'Connor MB et al. Adherence to anti-retroviral therapy among HIV patients in Bangalore. India AIDS Research and Therapy 2009;6:7.

11. Jayaram S, Shenoy S, Unnikrishnan B, Ramapuram J, Rao M. Profile of attendees in Voluntary Counseling and Testing Centers of a Medical College Hospital in Coastal Karnataka. Ind J Commuy Med 2008;33:43-6.
12. Safren $S A$, Kumarasamy $N$, James $R$, Raminani $\mathrm{S}$, Solomon S, Mayer KH. ART adherence, demographic variables and CD4 outcome among HIV-positive patients on antiretroviral therapy in Chennai, India. AIDS Care 2005; 17:853-862. ]

13. Sharma SK, Tamilarasu K, Banga A, Goyal T, Bhatia I, Saha PK. Spectrum of clinical disease in a series of 135 hospitalised HIV-infected patients from north India. BMC Infectious Diseases 2004;4:52-61.

14. Kumarasamy N, Solomon S, Chaguturu SK, Cecelia AJ, Vallabhaneni S, Flanigan TP, Mayer KH. The Changing Natural History of HIV Disease: Before and After the Introduction of Generic Antiretroviral Therapy in Southern India. CID 2005;41:1524-5.

15. Pant Pai N, Estes M, Moodie EM, Reingold AL, Tulsky JP. The Impact of Antiretroviral Therapy in a Cohort of HIV Infected Patients Going in and out of the San Francisco County Jail. PLoS ONE, 2009;4:e7115. 